\title{
A Case Management Model for Patients with Granulomatous Mastitis: A Prospective Study
}

Ping Ning ( $\nabla$ nping11@163.com )

Chengdu Women's and Children's Central Hospital, School of Medicine, University of Electronic Science and Technology of China, Chengdu, China.

\section{Yuan Deng}

Chengdu Women's and Children's Central Hospital, School of Medicine, University of Electronic Science and Technology of China, Chengdu, China.

\section{Ying Xiong}

Chengdu Women's and Children's Central Hospital, School of Medicine, University of Electronic Science and Technology of China, Chengdu, China.

\section{Xin Wang}

Chengdu Women's and Children's Central Hospital, School of Medicine, University of Electronic Science and Technology of China, Chengdu, China.

\section{Xiao-Rong Han}

Chengdu Women's and Children's Central Hospital, School of Medicine, University of Electronic Science and Technology of China, Chengdu, China.

\section{Guo-Fang Tu}

Chengdu Women's and Children's Central Hospital, School of Medicine, University of Electronic Science and Technology of China, Chengdu, China.

\section{Pei-Yu He}

Chengdu Women's and Children's Central Hospital, School of Medicine, University of Electronic Science and Technology of China, Chengdu, China.

\section{Research Article}

Keywords: granulomatous mastitis, case management, recurrence, medication adherence

Posted Date: January 28th, 2022

DOI: https://doi.org/10.21203/rs.3.rs-1267895/v1

License: (c) (i) This work is licensed under a Creative Commons Attribution 4.0 International License. Read Full License 


\section{Abstract}

Background: Granulomatous mastitis is a chronic inflammatory mastitis disease with long-term treatment and high recurrence rate, there is no general agreement on effective clinical management, the new management model is worthy of investigation. The aim of this study to investigate the application of case management model in granulomatous mastitis and explore the related factors which are associated with the recurrence of granulomatous mastitis.

Methods: This is a prospective study of 152 Chinese women who were monitored during the whole process of case management. Demographic, clinical and laboratory information, treatment methods, follow-up time, and recurrence were collected and analyzed. The eight-item Morisky medication adherence scale (MMAS-8) was used to investigate patients' adherence to medications.

Results: Until October 2021, a total of 152 female patients with a mean age of 32 years have received the entire process of case management. The mean total course of case management was 24.54 (range, 15 45) months. Almost all the patients received medication treatment, except for one pregnant patient on observation therapy, and about $53.9 \%$ of the patients had medication plus surgery. The overall recurrence rate was $11.2 \%$, and "high" medication adherence ( $R R=0.428,95 \% \mathrm{Cl}: 0.224-0.867, \mathrm{P}=0.015)$ were significantly associated with a lower rate of recurrence while the rate of recurrence with surgical procedure + medication was higher than that with medication treatment $(\mathrm{RR}=4.128,95 \% \mathrm{Cl}: 1.026$ $16.610, P=0.046)$.

Conclusion: case management model for patients with granulomatous mastitis was effective with a relatively low recurrence rate. "Low" medication adherence were significant risk factors for the recurrence of granulomatous mastitis. Patients with medication plus surgery are more likely to recur than with medication treatment alone. The optimal treatment approach should be planned for GM patient and patient's medication adherence should be of concern to medical staff.

\section{Background}

Granulomatous mastitis (GM) was firstly reported as a chronic inflammatory disease of the breast by Kessler and Wolloch in 1972 [1], accounting for approximately $1.8 \%$ of benign breast diseases [2]. Due to the rarity of the disease, most countries have not conducted large epidemiological surveys of granulomatous mastitis, with only 2.4 per 100,00 incidences reported from the Disease Control and Prevention in 2009 [3]. To date, the etiology of GM is unknown and may be associated with a history of pregnancy, autoimmune disease, breast trauma, hyperprolactinemia, and infection [15-16]. The disease progresses rapidly with a recurrent or prolonged natural course, which has a high recurrence rate of $5 \%-50 \%$, is commonly seen in young women with a history of breastfeeding and childbirth $[11,17,19,33]$. As recently been reported, there are racial differences in this disease, the incidence of GM in Middle Easterners (Egypt, Turkey, Iran) and Spaniards are higher than Western Caucasians (UK, USA, New Zealand) [5-7]. A large number of cases of granulomatous mastitis have been given descriptions, mainly 
from Asian and Mediterranean countries, such as China, Iran, and Turkey [8-9]. However, there is no consensus on the management of the disease and no gold standard regarding the diagnosis and treatment of GM [12]. Currently, the main treatment options have included observation, medication therapy (steroids, antibiotics, methotrexate (MTX), and anti-molecular bacilli) or/and operative intervention (abscess incision and drainage, simple mass excision, enlarged mammary mass excision, etc.) $[7,18]$. The main clinical presentation is a palpable, painful breast lump with concomitant skin erythema, nipple retraction, sinus tract formation, cellulitis changes, and axillary adenopathy formation [11-13], and in severe cases, there are usually multiple coexisting focal abscesses with skin inflammation and ulceration [13]. According to the severity of the disease, GM is clinically classified into the mass, the abscess, and the refractory type [14]. Patients often need to endure a long course of the disease, as well as changes in breast appearance brought about by the disease, which has serious physical and psychological effects on patients [16]. Meanwhile, the toxic side effects of long-term medication use have a significant impact on patients' quality of life, resulted in poor compliance with drug use, therefore, timely observation of medication use and changes in breasts is essential to achieve good recovery rates for GM patients [18-21].

Recently, case management has attracted more attention in medical practice as an approach to provide patients with regular and targeted disease monitoring and health guidance through follow-up visits and WeChat consultations [42]. In this model, nurse specialists is responsible for the overall coordination, management, and continuity of care for a specific treatment or intervention to meet the health needs of the individual, reduce health care costs and improve quality of service [22-23]. Currently, it is known that case management is widely applied to patients of breast disease, especially breast cancer [24-25], but is rarely to of GM. Since January 2018, case management model for GM patients had been explored and practiced in Chengdu Women's and Children's Central Hospital, which can provide patients with full management and seamless healthcare services.

\section{Materials And Methods}

\section{Study design and participants}

A prospective study on patients with granulomatous mastitis based on a case management model undertaken between January 2018 and November 2020 at the Breast Unit of the Chengdu Women's and Children's Central Hospital. According to characteristics of the disease, the whole process of case management presented in Figure 1 is divided into four key stages, including the diagnostic, the conservative, the perioperative, and the follow-up period. The entire period is led by case managers and tailored for patients, including evaluation, planning, integration, implementation, and evaluation of treatment plan. Participants were followed up by the whole process. At the diagnostic stage, case managers mainly based their decisions on clinical symptoms whether or not a register of initial medical history was created including age, pregnancy history, disease history, onset time, onset trigger, contact phone number. Patients whose diagnosis of granulomatous mastitis was confirmed by the results of pathological examination by core needle biopsy, and then case management file was established. At the 
conservative treatment stage, case managers mainly: (1) followed up and recorded the results of ultrasound, abnormal laboratory test and breast signs, and explained the precautions and methods of medication administration according to the doctor's prescription; (2) surveyed GM patients for medication adherence at 2 months of drug use. Adherence was measured using the eight-item Morisky Medication Adherence Scale (MMAS-8) [44], translated into Chinese scale by Lin Chen et al [45], which has a high reliability and validity, and has been widely used in studies of various chronic diseases in China $[45,46]$. Three levels of adherence were considered based on the following scores: 0 to $<6$ (low); 6 to $<8$ (medium); 8 (high). (3) handed out notes of disease considerations related to diet, sleep, behavior, etc. in Table 1 [14, 27, 28]; (4) established a contact platform for GM patients to know and observe the changes of their breasts during the treatment at home, given psychological support and guidance. In the perioperative and the follow-up period, the case manager recorded the patient's information of surgery, medication, follow-up time and recurrence.

In this study, the qualification of case managers only three were: (1) nurses with Bachelor's degree or above, (2) nurses with intermediate title or above, (3) 5 years or more in the breast department, (4) nurses who have received the training including case management process, communication and health promotion skills, (5) nurses who were required to rotate through the breast clinic, ultrasound and pathology department, wound care unit and operating room, (6) nurses who have passed the hospital examination of case management. All patients who received case management were eligible for inclusion if they were older than 18 years and had clinical signs on the breast, confirmed diagnosis by core needle biopsy. They were ineligible if they had other complications of the breast, and had been treated in other institutions. The study was approved by the ethics committee of the Chengdu Women's and Children's Central Hospital (No. B2019(13)). All participants signed an informed consent form.

\section{Case definition}

Histopathologic examination is a necessary and gold-standard method for diagnosis of granulomatous mastitis (GM) [43], so definitive diagnosis of GM is largely being accomplished with core needle biopsy in this study. The disease may be locally invasive with a risk of recurrence, recurrence rates of 5 to $50 \%$ have been observed following various literature in recent years $[17,19,33]$. The following definition of recurrence was used in this study: the detection of new lesion(s) within the range of the primary location or

any other part of the ipsilateral breast 1 month following the termination of therapy.

Medication adherence can be defined as the behavior about taking drugs that fits with the physician's advice [31]. In a meta analysis by Lei et al. [41], oral drug therapy is an effective treatment modality of GM patients in both surgical and conservative treatment. As the majority of the duration of drug application varied between 2 and 12 months [47, 48,49,50], we chose to investigate medication adherence at 2 months of medication. 


\section{Statistical analysis}

Statistical software package SPSS for Windows, version 19.0 (SPSS Inc., Chicago, IL) was used for statistical analysis. Clinical characteristics were descirbed using mean \pm standard deviation or mean (range) or number (and percentage) as appropriate. Continuous variables were compared between patients with and without recurrence using one-way ANOVA while categorical variables were compared using a Chi-square test and Fisher's exact tests. Logistic regression models were built for analysis of risk factors for the recurrence of GM.

\section{Results}

\section{Characteristics of the patients}

In this study, there were 204 symptomatic patients with granulomatous mastitis initially included in the diagnostic stage between January 2018 and November 2020. However, 4 patients were diagnosed as breast cancer, 8 dropped out and 42 still going on in case management. Ultimately, 152 patients have completed case management until September 2021. It is shown in Table 2 that the mean age of the patients was 32 years (range $22-48$ ). It was observed that $71(46.7 \%)$ patients had normal BMI, while 64 $(47,4 \%)$ patients' BMI was higher than 25 , which were considered as overweight or obese. It was detected that the period in which GM was most frequently seen was the first $2-5$ years after birth with 94 patients (61.8\%), followed by 30 patients (19.7\%) for $0-2$ years (4 patients in breastfeeding), 15 patients (9.9\%) for pregnancy. The accompanying diseases were found in only 28 (18.5\%) patients, such as diabetes mellitus, thyroid disease, psychoses, hypertension, and hyperprolactinemia accounted for $13.8 \%$ in the highest percentage of all comorbidities.

On physical examination, the most common finding was a palpable mass with pain (98.7\%), the breast abscess was in $38.8 \%$ of patients, and $75 \%$ of patients suffered from skin lesion, and approximately $5 \%$ had fistulas and Erythema nodosum (Table 2 ). Based on clinical symptoms, the disease was typed as the mass $(74,48.7 \%)$, the abscess $(66,43.4 \%)$, and the refractory type $(12,7.9 \%)$. Unilateral involvement was observed mostly in 140 (92.1\%) patients. In this study, 30.96\% of patients reported that they had bad behaviors a week before disease onset, including breast trauma (8.6\%), excitant food (14.47\%), staying up all night $(7.89 \%)$.

\section{Treatments of the patients}

It was seen in table 3 that different treatments were administered. Of 152 patients, only $1(0.7 \%)$ recovered under observation without treatment $₫ 82$ (53.9\%) recovered with medication plus surgery, 69 (45.4\%) recovered solely with medical treatment. In the course of medication $₫ 65$ (42.8\%囚patients chose systemic steroids alone, $21(13.7 \%)$ patients chose tubercle bacillus drug alone, while $65(42.8 \%)$ patients required a combination or change of drug regimen due to ineffective treatment or drug side effects 
including erythema nodosum (5.3\%), skin rash (5.3\%), abnormal index of liver function (7.2\%), abnormal uric acid $(2.0 \%)$ and edema on the lips and face $(0.7 \%)$.

\section{Follow-up visits for the patients}

The mean follow-up time was 25.55 months (range 15 - 45) in the patients treated with medication plus surgery, while it was 23.83 months (range $17-36$ ) in the patients treated solely with medication. There was no statistically significant difference between them $(p=0.570)$. The recurrence rate in the series was determined as $11.2 \%$ with 17 patients. At 2 months of initial medication, medication adherence outcome of GM patients was "high" in 59 patients (39\%), "Median" in 70 (46.4\%), and "Low" in 22 (14.6\%), shown in Table 4.

\section{Factors associated with recurrence}

All statistical significant variables related to BMI, treatments, medication and medication adherence (Table 5) were included in the multivariable logistic regression model. The results of the multivariable analysis are shown in Table 6, surgical procedure plus drug treatment ( $\mathrm{RR}=4.128,95 \% \mathrm{Cl}$ : 1.026-16.610, $\mathrm{P}=0.046$ ) were independently associated with increased recurrence risk of granulomatous mastitis. In contrast, "high" medication adherence ( $\mathrm{RR}=0.428,95 \% \mathrm{Cl}$ : $0.224-0.867, \mathrm{P}=0.015)$ was associated with decreased recurrence risk.

\section{Discussion And Conclusion}

This is the first study to report that a case management model is applied to GM. Although it is a benign disease, the recurrence of $\mathrm{GM}$, one of the main challenges in patients' management of the disease, has been reported to occur in $5 \%-50 \%$ of patients $[17,19,33]$. In our study, the recurrence rate of $11.2 \%$ lies in the low of this range. 17 patients with recurrence were including ten with new lesions in the ipsilateral breast and seven in the contralateral breast.

In recent years, the prevalence of granulomatous mastitis has been rapidly increasing, and most affected patients are women of childbearing age [64]. In two studies, Freeman et al. reported that up to $86 \%$ of GM patients had a history of pregnancy in the past 5 years [50]. Prasad et al. reported that 73 patients with GM had a mean age of approximately 33 years and a history of childbirth 4.6 years before mastitis on average [36]. In our study, the median age of patients was 32 years (range 22 - 48), 119 patients had a history of childbirth within 5 years, 15 patients had concurrent pregnancy, 4 patients were undergoing breastfeeding, which had similar characteristics as previously reported. It indicated that hormones play an important role and may be related to the secretion theory that has an important place in the pathophysiology of GM [33]. It has been postulated that GM results from a localized autoimmune response to the retained or extra vacated fat- or protein-rich secretion in the breast ducts during 
childbearing age due to previous hyperprolactinemia in women [40]. Therefore, the breast care for women of childbearing age should deserve our attention.

GM patients mostly have mass and pain symptoms, skin lesion and abscess can be observed in the mass localization. Findings such as fistula, erythema nodosum, and nipple or skin retraction can also be observed [1, 2, 47]. In many studies, the most common complaint at the time of initial visit was reported as unilateral painful breast mass $[26,47]$. Similarly, $98.7 \%$ of the patients had mass and pain complaint, $92.1 \%$ of the patients presented as a unilateral affected breast. The case managers would make initial judgments and tendentious guidance based on clinical presentations. At the initial visit, there were the mass $(74,48.7 \%)$, the abscess $(66,43.4 \%)$, and the refractory type $(12,7.9 \%)$, which were not associated with recurrence in the later stages $(P=0.2)$. As the disease progresses, 10 cases of the mass type turned to the abscess and 4 cases of the abscess turned to the refractory. The important thing for case managers is the care of the affected breast (shown in Fig. 2 and Fig. 3). Wound care should consist of managing drainage from fistulae with gauze and other non-adherent dressings. Tape should be avoided due to further abrasion and irritation of the skin [38]. Meanwhile, if the patient has a superficial abscess, a case manager percutaneously performs puncture aspiration, and how deep the abscess is, the mammographer is assisted by ultrasound guidance to perform puncture drainage, in order to create a path for drainage of secretions and reduction of pressure in the inflamed area due to the accumulation of inflammatory fluid.

Comparing the most recent publications on GM to older data, there is no new information on this benign breast disease. Therefore, the best management of this disease is still unclear $[19,33]$. The usual treatment for GM is close observation, medical treatment, surgical management, or a combination of both $[7,11,37]$. In the present study, only $1(0.7 \%)$ recovered under observation, 82 (53.9\%) recovered with medication plus surgery (such as shown in fig.2), 69 (45.4\%) recovered solely with medication treatment (such as shown in fig.3). Multivariate analysis revealed that medication plus surgery was significantly associated with recurrence $(\mathrm{RR}=4.128,95 \% \mathrm{Cl}[1.026$ 16.610], $P=0.0046$ ) (Table 6). Regarding the cause of recurrence, previous studies have ascribed the incompleteness of excision to the failure of surgical treatment, or it is likely that inconsistent follow-up times. In this study, case managers would assess changes in the size of the breast mass and the proportion of the mass size to the breast size and consider whether the patients can undergo surgical excision with minimal impact on the aesthetics of the breast. The breast lesion excision by minimally invasive surgery or open surgery were applied, which may be a risk of incomplete surgical excision. Akcan et al. and Yabanoğlu H et al. reported that complete excision of the breast or wide excision with or without medication achieved low recurrence rates $[10,50]$, however, it is possible to cause appearance damage of breast due to excessive removal of tissues. Thereby, The biggest problem with surgical treatment is the contradiction between the surgical effect and the postoperative aesthetic effect. Whether surgery which procedure to choose increases the recurrence rate of $\mathrm{GM}$, it is required that more evidences are to be further investigated. 
Our study demonstrated that medical treatment is most prevalent, whether coupled with surgical treatment or not. The drug therapies have numerous side effects, such as Cushion's syndrome skin rash, abnormal liver enzymes and uric acid and so on [51]. In our study, there are $8(5.3 \%)$ patients suffering skin rash, 11 (7.2\%) abnormal liver enzymes, 3 (2.0\%) abnormal uric acid, and 1 (0.7\%) edema on the lips and face (shown in Table 3). In this stage, case managers serve as a treatment team by linking physicians, pharmacists, dermatologists, obstetricians, and general practitioners. They communicated with the multidisciplinary team immediately, and then guided the patient on their medications, and then finally most of the side effects disappeared within 1 week.

To the best of our knowledge, there are no studies investigating medication adherence in GM patients. In our study, it has been shown that the MMAS-8 was responded by 154 patients that had $39 \%$ high adherers, $46.4 \%$ medium adherers, and $14.6 \%$ low adherers. As a result of case manager guidance, "Low" medication adherence of GM was much lower than reported $30 \%$ and $50 \%$ of poor adherence to chronic disease in adults [29,30]. Furthermore, "High" medication adherence (RR=0.428, 95\% Cl: 0.224-0.867, P = 0.015 ) at two months of initial medication were significantly associated with a lower rate of recurrence in multivariate analysis. At the initial stage, the case managers paid more attention to the changes in the patient's breast symptoms than patient medication adherence, the medical staff's guidance and supervision of patient medication needs more improvement. Currently, several reports have demonstrated the importance of regular visits to the physician, adequate patient contact time in clinical practice, and patient education to improve medication adherence to treatment $[4,32]$.

In this study, the results were found that $22(14.47 \%)$ patients had excitant food before the onset of GM. The recent literature reported that bacterial interactions have been confirmed between the breast and gut $[34,35,39]$. Li XQ et al hypothesized that imbalances among the external environment, host, and microbiota lead to the occurrence of GM as follows: External factors disturb the balance between the immune microenvironment and breast flora and induce the release of inflammatory factors and milk secretion, resulting in damage to the mammary epithelium. The positive feedback between the immune and inflammatory reactions eventually induces GM [34]. Consumption of stimulating foods may disrupt intestinal flora and induce inflammation. Therefore, the patients with GM will be handed out notes of disease considerations related to dietary, sleep, behavior, etc. in Table 1. Due to the limitations of this study, it cannot be confirmed whether GM is related to dietary and lifestyle habits, which needs to be further investigated.

In conclusion, case management is effective for patients with GM. It made healthcare services and health information easy to access for GM patients and had relatively low recurrence rate. The optimal treatment approach should be planned for GM patient and patient's medication adherence should be of concern to medical staff.

\section{Declarations}

\section{Ethics approval and consent to participate}


This study was approved by the Institution Review Board of Chengdu Women and Children's Central Hospital Ethical approval (Grant No. B2019(13)). All participants signed an informed consent form before data collection. All procedures performed in this study were in accordance with the ethical standards.

\section{Consent for publication}

Not applicable

\section{Availability of data and materials}

The data that support the findings of this study are available from the corresponding author upon reasonable request.

\section{Competing interests}

The author(s) declared no potential conflicts of interest with respect to the research, authorship, and/or publication of this article.

\section{Funding}

The author(s) disclosed receipt of the following financial support for the research, authorship, and/or publication of this article: This work was supported by the Science and Technology Project of Sichuan Provincial Health Commission [Grant No. 21PJ134].

\section{Author Contributions}

Contributions to conception and design: P.N., X.W., X-R. H, Y.D., Y. X., G-F.T.

Data Collection \& Collation: Y.D., Y.X., P-Y.H.

Writing - original draft: Y.D., Y.X.

Critical revision for important intellectual content: P.N., X.W.

Y.D. and Y.X. contributed equally to this work.

All authors reviewed the manuscript.

\section{Acknowledgements}


None.

\section{References}

1. Kessler E, Wolloch Y: Granulomatous mastitis: a lesion clinically simulating carcinoma. AM J Clin Pathol 1972;58:642-646.

2. Baslaim MM, Khayat HA, Al-Amoudi SA. Idiopathic granulomatous mastitis: a heterogeneous disease with variable clinical presentation. World J Surg. 2007;31(8):1677-1681. doi:10.1007/s00268-0079116-1.

3. Centers for Disease Control and Prevention: Idiopathic granulomatous mastitis in Hispanic women Indiana, 2006-2008. MMWR Morb Mortal Wkly Rep 2009;58:1317-1321.

4. Marengo MF, Suarez-Almazor ME. Improving treatment adherence in patients with rheumatoid arthritis: what are the options? Int J Clin Rheumtol 2015;10:345-56. mastitis: Local heat therapy

5. Barreto DS, Sedgwick EL, Nagi CS, Benveniste AP. Granulomatous mastitis: etiology,imaging, pathology, treatment, and clinical findings. Breast Cancer Res Treat 2018;171:527-534.

6. Helal TEA, Shash LS, Saad El-Din SA, Saber SM. Idiopathic granulomatous mastitis: cytologic and histologic study of 65 Egyptian patients. Acta Cytologica 2016;60:438-444.

7. Sheybani F, Naderi HR, Gharib M, Sarvghad MR, Mirfeizi Z. Idiopathic granulomatous mastitis: longdiscussed but yet-to-be-known. J Autoimmun 2016;49:236-239.

8. Al Manasra AR, Al-Hurani MF. Granulomatous mastitis: a rare cause of male breast lump. Case Rep Oncol. 2016;9(2):516-9.

9. Velidedeoglu M, Kilic F, Mete B, Yemisen M, Celik V, Gazioglu E, et al. Bilateral idiopathic granulomatous mastitis. Asian J Surg. 2016;39(1):12-20.

10. Yabanoğlu H, Çolakoğlu T, Belli S, Aytac HO, Bolat FA, Pourbagher A, et al. A Comparative Study of Conservative versus Surgical Treatment Protocols for 77 Patients with Idiopathic Granulomatous Mastitis. Breast J. 2015 Jul Aug;21(4):363-9

11. Li J. Diagnosis and treatment of 75 patients with idiopathic lobular granulomatous mastitis. J Invest Surg. 2019;32(5):414-420.doi:10.1080/08941939.2018.1424270.

12. Steuer AB, Stern MJ, Cobos $G$, et al. Clinical characteristics and medical management of idiopathic granulomatous mastitis. JAMA Dermatol. 2020;156(4):460-1001.

doi:10.1001/jamadermatol.2019.4516.

13. Lai ECH, Chan WC, Ma TKF, et al. The role of conservative treatment in idiopathic granulomatous mastitis. Breast J. 2005;11(6):454-456. doi:10.1111/j.1075-122X.2005.00127.x.

14. Wang, Qi, Yu, Haijing. Precision diagnosis and treatment of granulomatous mastitis[J]. Chinese Journal of Breast Diseases (electronic version),2017,03:129-131.

15. Al-Khaffaf B, Knox F, Bundred NJ. Idiopathic granulomatous mastitis: a 25-year experience. J Am Coll Surg. 2008.;206(2):269-273.doi:10.1016/j.jamcollsurg.2007.07.041. 
16. Wang J, Xu H, Li Z, et al. Pathogens in patients with granulomatous lobular mastitis. Int J Infect Dis. 2019; 81:123-127. doi:10.1016/j.ijid.2019.01.034.

17. Aghajanzadeh M, Hassanzadeh R, Alizadeh Sefat S, et al.Granulomatous mastitis: Presentations, diagnosis, treatment and outcome in 206 patients from the north of Iran. Breast. 2015;24(4):456460. doi:10.1016/j.breast.2015.04.003.

18. Akbulut S, Yilmaz D, Bakir S. Methotrexate in the management of idiopathic granulomatous mastitis: review of 108 published cases and report of four cases. Breast J. 2011;17(6):661-668.

19. Hovanessian Larsen LJ, Peyvandi B, Klipfel N, Grant E, lyengar G. Granulomatous lobular mastitis: imaging, diagnosis, and treatment. AJR Am J Roentgenol. 2009 Aug;193(2):574-81.

20. Hur SM, Cho DH, Lee SK, Choi MY, Bae SY, Koo MY, et al. Experience of treatment of patients with granulomatous lobular mastitis. J Korean Surg Soc. 2013 Jul;85(1):1-6.

21. Mahlab-Guri K, Asher I, Allweis T, Diment J, Sthoeger ZM, Mavor E. Granulomatous Lobular Mastitis. Isr Med Assoc J. 2015 Aug;17(8):476-80.

22. Hisashige A. The effectiveness and efficiency of disease management programs for patients with chronic diseases. Glob J Health Sci. 2013;5:27-48.

23. Tokem Y, Argon G, Keser G. Case management in care of Turkish rheumatoid arthritis patients. Rehabil Nurs. 2011;36:205-213.

24. Hubbard G, Gray N M, Ayansina D, et al. Case Management Vocational Rehabilitation for Women with Breast Cancer after Surgery: A Feasibility Study Incorporating a Pilot Randomized Controlled Trial [ J ]. Trials, 2013,14 (1):175-188. DOI: 10.1186/1745-6215-14-175.

25. Scherz N, Bachmann-Mettler I,Chmiel C, et al. Case Management to Increase Quality of Life after Cancer Treatment: A Randomized Controlled Trial [ J ] BMC Cancer, 2017, 17 (1):223230.DOI:10.1186/s12885-017-3213-9.

26. Gupta N, Vats M, Garg M, Dahiya DS. Bilateral idiopathic granulomatous mastitis. BMJ Case Rep. 2020 Aug 31;13(8):e234979.doi:10.1136/bcr-2020-234979.PMID: 32868320; PMCID: PMC7462244.

27. Benson JR, Dumitru D: Idiopathic granulomatous mastitis: presentation, investigation and management. Future Oncol. 2016, 12:1381-94. 10.2217/fon-2015-0038.

28. Ozel L, Unal A, Unal E, et al. Granulomatous mastitis: is it an autoimmune disease? Diagnostic and therapeutic dilemmas.Surg Today. 2012;42:729e733.

29. Briesacher BA, Andrade SE, Fouayzi H, Chan KA. Comparison of drug adherence rates among patients with seven different medical conditions. Pharmacotherapy. 2008;28(4):437-443. doi:10.1592/phco.28.4.437

30. Naderi SH, Bestwick JP, Wald DS. Adherence to drugs that prevent cardiovascular disease: metaanalysis on 376,162 patients. Am J Med. 2012;125(9):882-887. doi:10.1016/j.amjmed.2011.12.013

31. Wabe N, Wiese MD. Treating rheumatoid arthritis to target: physician and patient adherence issues in contemporary rheumatoid arthritis therapy. J Eval Clin Pract 2017;23:486-93. 
32. Gadallah MA, Boulos DN, Gebrel A, Dewedar S, Morisky DE. Assessment of rheumatoid arthritis patients' adherence to treatment. Am J Med Sci 2015;349:151-6.

33. Lin $\mathrm{CH}$, Hsu CW, Tsao TY, et al. Idiopathic granulomatous mastitis associated with risperidoneinduced hyperpro actinemia. Diagn Pathol 2012;7:2.

34. Li XQ, Wu HL, Yuan JP, Liu TG, Sun SR, Chen C. Bacteria Associated with Granulomatous Lobular Mastitis and the Potential for Personalized Therapy. J Invest Surg. 2020 Oct 15:1-7. doi: 10.1080/08941939.2020.1833262. Epub ahead of print. PMID: 33059500.

35. Hu X, Li S, Fu Y, Zhang N. Targeting gut microbiota as a possible therapy for mastitis. Eur J Clin Microbiol Infect Dis. 2019 Aug;38(8):1409-1423. doi: 10.1007/s10096-019-03549-4. Epub 2019 May 11. PMID: 31079312.

36. Prasad S, Jaiprakash P, Dave A, Pai D. Idiopathic granulomatous mastitis: an institutional experience. Turk J Surg 2017;33(2):100e3.

37. Gunduz Y, Altintoprak F, Tatli Ayhan L, Kivilcim T, Celebi F. Effect of topical steroid treatment on idiopathic granulomatous mastitis: clinical and radiologic evaluation. Breast J. 2014 NovDec;20(6):586-91.

38. Wang J, Zhang Y, Lu X, Xi C, Yu K, Gao R, Bi K. Idiopathic Granulomatous Mastitis with Skin Rupture: A Retrospective Cohort Study of 200 Patients Who Underwent Surgical and Nonsurgical Treatment. J Invest Surg. 2019 Dec 10:1-6. doi: 10.1080/08941939.2019.1696905. Epub ahead of print. PMID: 31818161.

39. Hu X, Li S, Fu Y, Zhang N. Targeting gut using with breast carcinoma. Breast Cancer Res Treat. 2010;123(2):447-52. https://doi.org/10.10icrobiota as a possible therapy for mastitis. Eur J Clin Microbiol Infect Dis. 2019;38(8):1409-1423. doi:10.1007/s10096-019-03549-4.

40. Agrawal A, Pabolu S. A Rare Case of Idiopathic Granulomatous Mastitis in a Nulliparous Woman with Hyperprolactinemia. Cureus. 2019 May 16;11(5):e4680. doi: 10.7759/cureus.4680. PMID: 31328071 ; PMCID: PMC6634339.

41. Lei X, Chen K, Zhu L, et al: Treatments for idiopathic granulomatous mastitis: systematic review and meta analysis. Breastfeed Med 2017; 12: 415-421.

42. Xing Weijie, Huang Jialing, Lu Zhengqi, et al. The effect of case management nursing practice on improving the quality of life of breast cancer patients. Chinese Journal of Nursing, 2011, 46, 10531056.

43. Kaviani, A.; Vasigh, M.; Omranipour, R.; Mahmoudzadeh, H.; Elahi, A.; Farivar, L.; Zand, S. Idiopathic granulomatous mastitis: Looking for the most effective therapy with the least side effects according to the severity of the disease in 374 patients in Iran. Breast J. 2019, 25, 672-677.

44. Morisky, D. E., Ang, A., Krousel-Wood, M., \& Ward, H. J. (2008). Predictive validity of a medication adherence measure in an outpatient setting. Journal of clinical hypertension (Greenwich, Conn.), 10(5), 348-354. https://doi.org/10.1111/j.1751-7176.2008.07572.x

45. Lin Chen, Zhang Chungee, Shu Liya, Chen Rong \& Wu Jian. (2020). Current status and pharmacological monitoring of long-term oral glucocorticoid patients in rheumatology department. 
Chinese Journal of Hospital Pharmacy (09), 1020-1026. doi:10.13286/j.1001-5213.2020.09.13.

46. Wu F, Zhao JX, Wang TS, Shao H \& Shi LW. (2018). Reliability analysis of Chinese version of MMAS8 to measure medication adherence in patients with rheumatoid arthritis. Chinese Pharmacy (02),263-268. doi:CNKI:SUN:ZGYA.0.2018-02-028.

47. Freeman $\mathrm{CM}, \mathrm{Xia} \mathrm{BT}$, Lewis JD, et al: Idiopathic granulomatous mastitis: a diagnostic and therapeutic challenge. Am J of Surg 2017; 214: 701-706.

48. Keller K, Meisel C, Petzold A, Wimberger P: Granulomatöse Mastitis - möglicher diagnostischer und therapeutischer Ablauf anhand von Fallbeispielen. Senologie 2018; 15:e23.

49. DeHertogh DA, Rossof $A H$, Harris $A A$, et al: Prednisone management of granulomatous mastitis. $N$ Engl J Med 1980; 303: 799-800.

50. Akcan A, Öz AB, Dogan S, et al: Idiopathic granulomatous mastitis: comparison of wide local excision with or without corticosteroid therapy. Breast Care 2014; 9: 111-115.

51. D. alcin Kehribar, T. Izci Duran, A. Kamali Polat, et al., Ab1053Effectiveness of methotrexate in idiopathic granulomatous mastitis treatment, Ann. Rheum. Dis. 79 (2020) 1816-1817.

\section{Tables}

\section{Table 1}

Notes of disease considerations

\begin{tabular}{|l|l|}
\hline Contents & Cautions \\
\hline Dietary $[14,35]$ & $\begin{array}{l}\text { Meat: meat other than pork } \\
\text { Seafood: seaweed, laver, etc. } \\
\text { FaWu (name from China): mushrooms, bamboo shoots, etc. } \\
\text { Tropical fruits: cinnamon, mango, durian, etc. } \\
\text { Spicy food: hot pot, barbecue, etc. }\end{array}$ \\
\hline Behavior $[27,28]$ & $\begin{array}{l}\text { Breast collision } \\
\text { Consumption of alcohol and tobacco } \\
\end{array}$ \\
& Poor sleep and emotions \\
& Pregnancy during the treatment period \\
\hline
\end{tabular}

Table 2

Demographic and clinical characteristics of 152 patients 


\begin{tabular}{|c|c|}
\hline Variables & Patients $(n=152)$ \\
\hline Age, mean (SD) [range], y & $32 \rrbracket 4 \rrbracket[22-48]$ \\
\hline \multicolumn{2}{|l|}{$\mathrm{BMI}\left(\mathrm{kg} / \mathrm{m}^{2}\right)$} \\
\hline$\geq 30$ & $8 \rrbracket 5.3 \% \bigotimes$ \\
\hline $25-30$ & $64 \llbracket 42.1 \% \rrbracket$ \\
\hline 18.5-24.99 & $71 \llbracket 46.7 \% \bigotimes$ \\
\hline$\nabla 18.5$ & $9 \otimes 5.9 \% \bigotimes$ \\
\hline \multicolumn{2}{|c|}{ Time interval between birth and onset of GLM (years) } \\
\hline Pregnancy & $15 \rrbracket 9.9 \% \rrbracket$ \\
\hline Breastfeeding & $4 \rrbracket 2.6 \% \bigotimes$ \\
\hline Time until last birth (y) ( $₫ 2 \rrbracket$ no breastfeeding) & $26 \llbracket 17.1 \% \rrbracket$ \\
\hline Time until last birth (y) (2-5) & $94 \llbracket 61.8 \% \rrbracket$ \\
\hline 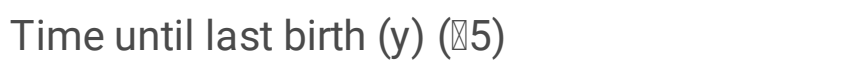 & $8 \bigotimes 5.3 \% \bigotimes$ \\
\hline No birth & $5 \rrbracket 3.3 \% \bigotimes$ \\
\hline \multicolumn{2}{|l|}{ Comorbid disease } \\
\hline Diabetes mellitus & $1 \rrbracket 0.7 \% \rrbracket$ \\
\hline Thyroid disease & $1 \otimes 0.7 \% \bigotimes$ \\
\hline Psychoses & $3 \rrbracket 2.0 \% \rrbracket$ \\
\hline Hypertension & $2 \bigotimes 1.3 \% \bigotimes$ \\
\hline Hyperprolactinemia & $21 \rrbracket 13.8 \% \rrbracket$ \\
\hline \multicolumn{2}{|l|}{ Side } \\
\hline Left & $81 \llbracket 53.2 \% \bigotimes$ \\
\hline Right & $59 \llbracket 38.9 \% \rrbracket$ \\
\hline Bilateral & $12 \bigotimes 7.9 \% \rrbracket$ \\
\hline \multicolumn{2}{|l|}{ Sign and symptoms } \\
\hline Palpable mass with pain & $150 \otimes 98.7 \% \rrbracket$ \\
\hline Skin lesion & $114 \otimes 75 \% \rrbracket$ \\
\hline Abscess & $64 \llbracket 38.8 \% \rrbracket$ \\
\hline Fistula & $8 \bowtie 5.3 \% \rrbracket$ \\
\hline
\end{tabular}




\section{Mass size at onset[43]}

\begin{tabular}{ll}
$<1 \mathrm{~cm}$ & $6(4.2 \%)$ \\
\hline $1-2 \mathrm{~cm}$ & $40 \otimes 26.3 \% 区$ \\
\hline $3-5 \mathrm{~cm}$ & $69(45.6 \%)$ \\
$>5 \mathrm{~cm}$ & $36(23.9 \%)$
\end{tabular}

\section{Laboratory tests before treatment}

C. kroppenstedtii

Positive

White blood cell (WBC)

mean [range], *10^9/L

C-reactive protein (CRP)

mean [range], mg/L

Prolactin(PRL)

mean [range], $\mathrm{ng} / \mathrm{mL}$

\section{Types of GM}

Mass type

Abscess type

Refractory type

Behavior before the onset

Breast trauma

Excitant food

Staying up all night
$28 \otimes 18.4 \% \bigotimes$

$9.77 \pm 3.33(3.59-17.55)$

$11.91 \pm 18.91$ (1.0-139)

$22.70 \pm 19.72(3.5-129.24)$ 
Variables

Patients

$(n=152)$

\section{Treatments}

Medication + surgery

$80 \rrbracket 52.6 \% \rrbracket$

Medication

$71 \rrbracket 46.7 \% \rrbracket$

Observation

$1(0.7 \%)$

\section{Medication}

Single steroids

$84 \rrbracket 55.6 \% \rrbracket$

Single tubercle bacillus drug

$20 \otimes 13.2 \% \rrbracket$

Combined medication

$47 \rrbracket 31.2 \% \rrbracket$

( antibiotics and/or steroids and/or

methotrexate and/or tubercle bacillus drug and/or

immunosuppressants and/or bromocriptine $\mathbb{Z}$

\section{Surgery}

Breast lesion excision by minimally invasive surgery

$20(13.2 \%)$

Breast lesion excision by open surgery

$60(39.5 \%)$

Without surgery

$72 \llbracket 47.4 \% \rrbracket$

\section{Side effects}

Skin rash

$8 \llbracket 5.3 \% \rrbracket$

Abnormal index of liver function

$11 \rrbracket 7.2 \% \bigotimes$

Abnormal uric acid

$3 \varangle 2.0 \% \rrbracket$

edema on the lips and face

$1 \rrbracket 0.7 \% \rrbracket$

\section{Table 4}

Follow-up visit of patients 


\begin{tabular}{|c|c|}
\hline Variables & Patients $(n=152)$ \\
\hline Follow-up time, mean (SD) [range], $m$ & $24.54(4.38)[15-45]$ \\
\hline Medical + Breast lesion excision by minimally invasive surgery & $26.38 \square 8.27 \bigotimes[15-45]$ \\
\hline Medical + Breast lesion excision by open surgery & $24.72 \square 3.97 \otimes[17-36]$ \\
\hline Medical & $23.83(2.62)[16-30]$ \\
\hline Observation & 12 \\
\hline \multicolumn{2}{|l|}{ recurrence } \\
\hline Yes & $17(11.2 \%)$ \\
\hline No & $135(88.8 \%)$ \\
\hline \multicolumn{2}{|l|}{ Medication adherence } \\
\hline High & $59(39.0 \%)$ \\
\hline Median & $70(46.4 \%)$ \\
\hline Low & $22(14.6 \% \square$ \\
\hline
\end{tabular}

Table 5

The characteristics in GM patients with and without recurrence 
Variables

No recurrence
Recurence

Test statistic
$\mathrm{BMI}\left(\mathrm{kg} / \mathrm{m}^{2}\right)$

18.5-24.99

ه18.5

25-29.99

$\geq 30$

Side

Right

Left

Bilateral

Mass size at onset

$<1 \mathrm{~cm}$

$1-2.9 \mathrm{~cm}$

3-5 cm

$>5 \mathrm{~cm}$

Laboratory tests before treatment

C. kroppenstedtii

Positive

Negative

White blood cell (WBC)

mean, ${ }^{*} 10^{\wedge} 9 / \mathrm{L}$

C-reactive protein (CRP)

mean, $\mathrm{mg} / \mathrm{L}$

Prolactin (PRL)

$22.1 \pm 19.8$

5 (3.7)

31 (22.9区

65 (48.2)

34 (25.2)

$$
\chi^{2}=3.234
$$

0.345

$6(35.3)$

$8(47.1)$

$3(17.6 \rrbracket$ $\chi^{2}=1.031 \quad 0.797$

1 (5.9)

4 (23.5)

7 (41.2)

5 (29.4) \\ $\chi^{2}=8.29 \quad 0.028$}

\begin{tabular}{ll}
$53(39.2)$ & $6(35.3)$ \\
\hline $73(54.1 \rrbracket$ & $8(47.1)$ \\
$9(6.7)$ & $3(17.6 \rrbracket$
\end{tabular}




\begin{tabular}{|c|c|c|c|c|}
\hline Abscess type & $59(43.7 \rrbracket$ & $7(41.2 \rrbracket$ & & \\
\hline Refractory type & $11(8.1 \rrbracket$ & $1(5.9 \bigotimes$ & & \\
\hline Treatments & & & $\begin{array}{l}\chi^{2}= \\
7.429\end{array}$ & 0.02 \\
\hline $\begin{array}{l}\text { Medical + Breast lesion excision by minimally } \\
\text { invasive surgery }\end{array}$ & $17(12.7)$ & $2(11.8)$ & & \\
\hline Medical + Breast lesion excision by open surgery & $50(37.0)$ & $12(70.6)$ & & \\
\hline Medication & $67(49.6)$ & $3(17.6)$ & & \\
\hline Observation & $1(0.7)$ & 0 & & \\
\hline Medication & & & $\begin{array}{l}\chi^{2}= \\
7.175\end{array}$ & 0.018 \\
\hline Single steroids & $77(57.0)$ & $7(41.2)$ & & \\
\hline Single tubercle bacillus drug & $20(14.8)$ & 0 & & \\
\hline Combined medication & $37(27.5)$ & $10(58.8)$ & & \\
\hline Without medication & $1(0.7)$ & 0 & & \\
\hline Medication adherence & & & $\begin{array}{l}\chi^{2}= \\
5.932\end{array}$ & 0.046 \\
\hline Low & $17 \otimes 12.7 \rrbracket$ & $6 \rrbracket 35.3 \rrbracket$ & & \\
\hline Median & $63 \rrbracket 47.0 \rrbracket$ & $8 \bowtie 47.1 \rrbracket$ & & \\
\hline High & $54 \rrbracket 40.3 \rrbracket$ & $3 \bigotimes 17.6 \rrbracket$ & & \\
\hline Follow-up time, $\mathrm{m}$ & 24.55 & 24.41 & $F=0.015$ & 0.901 \\
\hline
\end{tabular}

\section{Table 6}

Risk factors for GM recurrence by multivariate analysis 


\begin{tabular}{llll} 
Variables & Rate ratio & $95 \% \mathrm{Cl}$ & $\mathrm{P}[$ \\
\hline BMI $\left(\mathrm{kg} / \mathrm{m}^{2}\right)$ & & & \\
\hline$\unrhd 24.99$ & 1 & Reference & 0.166 \\
\hline $25-30$ & 3.467 & $0.949-12.666$ & 0.060 \\
\hline$\geq 30$ & 3.245 & $0.269-39.211$ & 0.355 \\
\hline Treatments & & & \\
\hline Medication & & Reference & \\
\hline Medical + surgery & 4.128 & $1.026-16.610$ & 0.046 \\
\hline Medication & & & \\
\hline Single medication & & Reference & \\
\hline Multiple medication & 2.556 & $0.821-7.957$ & 0.105 \\
\hline Medication adherence & & & \\
\hline Low & & Reference & 0.046 \\
\hline Median & 0.656 & $0.160-1.182$ & 0.064 \\
\hline High & 0.428 & $0.224-0.867$ & $\mathbf{0 . 0 1 5}$
\end{tabular}

Figures 


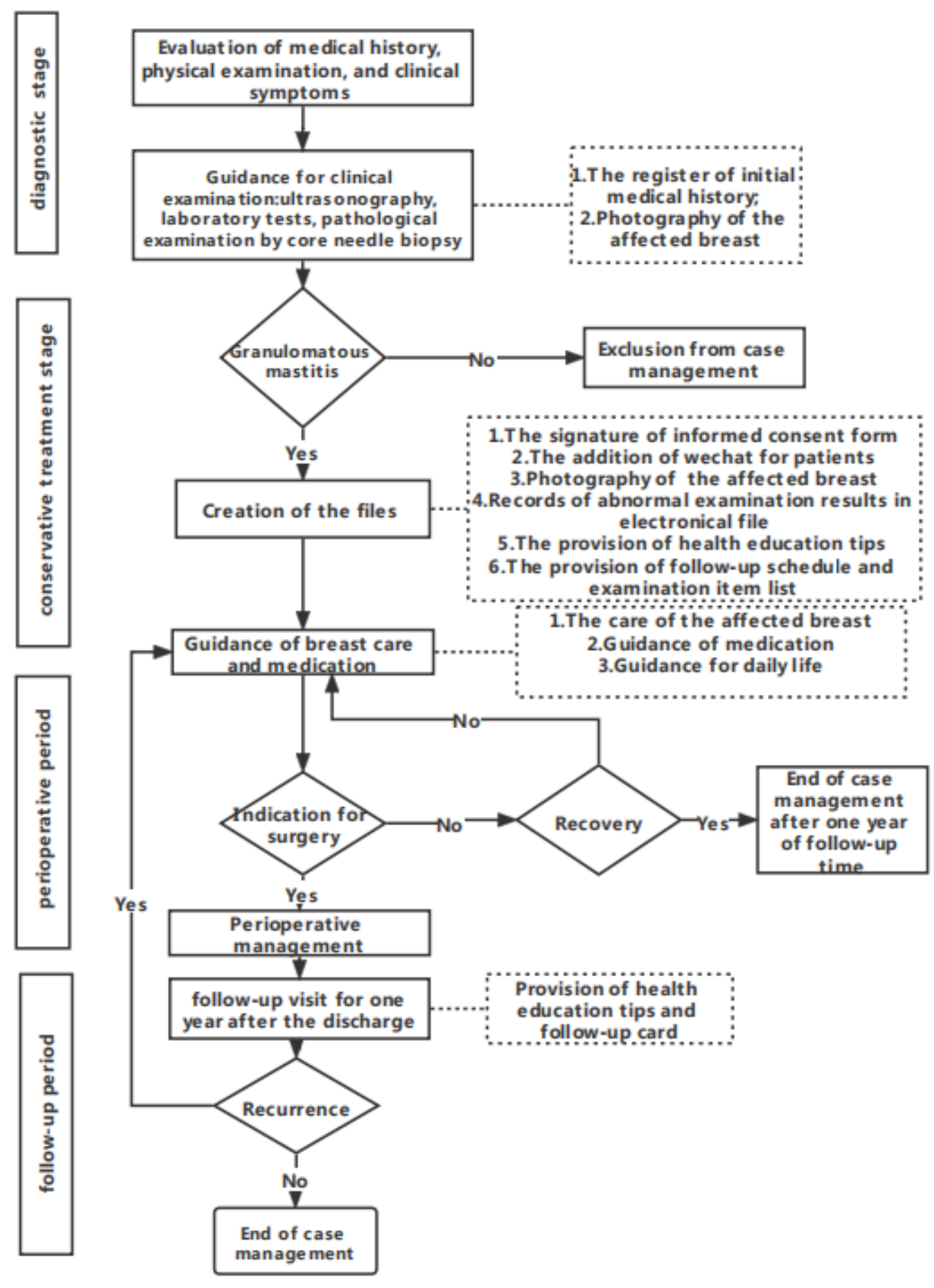

\section{Figure 1}

the algorithm for the case management of granulomatous mastitis 


\section{Figure 2}

The effect of medical and surgical treatment under the case management. The underlined part of the figure shows the scope of the lesion located by ultrasound. 
Figure 3

The effect of medical treatment under the case management. 